\title{
Human-induced pluripotent stem cell- derived macrophages and their immunological function in response to tuberculosis infection
}

Danping Hong ${ }^{1,2}$, Jiongyan Ding ${ }^{1,2}$, Ouyang Li ${ }^{1,2}$, Quan He ${ }^{1,2}$, Minxia Ke $e^{1,2}$, Mengyi Zhu ${ }^{1,2}$, Lili Liu ${ }^{1,2}$, Wen-Bin Ou ${ }^{1,2}$, Yulong $\mathrm{He}^{1,2^{*}}$ and Yuehong $\mathrm{Wu}^{1,2^{*}}$

\begin{abstract}
Background: Induced pluripotent stem cells (iPS) represent an innovative source for the standardized in vitro generation of macrophages $(M \varphi)$. $M \varphi$ show great promise in disease pathogenesis, particularly tuberculosis. However, there is no information about human iPS-derived (hiPS) macrophages (hiPS-M $\varphi$ ) in response to tuberculosis infection.

Methods: In the present study, macrophages derived from hiPS were established via embryoid body (EB) formation by using feeder-free culture conditions, and the human monocyte cell line THP-1 (THP-1-M $\varphi$ ) was used as control. iPS-M $\varphi$ were characterized by using morphology, Giemsa staining, nonspecific esterase staining (a-NAE), phagocytosis, and surface phenotype. Additionally, after treatment with Bacillus Calmette-Guérin (BCG) for 24 h, cell apoptosis was detected by using an Annexin V-FITC Apoptosis Detection assay. The production of nitric oxide (NO), expression of tumor necrosis factor alpha (TNF-a), activity of apoptosis-related protein cysteine-3 (Caspase-3) and expression of B-cell lymphoma-2 (Bcl-2) were analyzed.

Results: With respect to morphology, surface phenotype, and function, the iPS-M $\varphi$ closely resembled their counterparts generated in vitro from a human monocyte cell line. IPS-M $\varphi$ exhibited the typically morphological characteristics of macrophages, such as round, oval, fusiform and irregular characteristics. The cells were Giemsa-stained-positive, a-NAE-positive, and possessed phagocytic ability. iPS-M $\varphi$ express high levels of CD14, CD11b, CD40, CD68, and major histocompatibility complex II (MHC-II). Moreover, with regard to the apoptotic rate, the production of NO, expression of TNF-a, and activity of Caspase-3 and BCl-2, iPS-M $\varphi$ closely resemble that of their counterparts generated in vitro from human monocyte cell line in response to BCG infection. The rate of apoptosis of BCG-treated IPS-M $\varphi$ was $37.77 \pm 7.94 \%$ compared to that of the untreated group at $4.97 \pm 1.60 \%(P<0.01)$ by using Annexin V-FITC Apoptosis Detection. Additionally, the rate of apoptosis of BCG-treated THP-1-M $\varphi$ was $37.1 \pm 2.84 \%$ compared to that of the untreated group at $6.19 \pm 1.68 \%(P<0.001)$. The expression of TNF-a and the production of NO were significantly increased $(P<0.001)$, and the activity of Caspase-3 was increased. However, the expression of Bcl-2 was inhibited $(P<0.001)$.

(Continued on next page)
\end{abstract}

\footnotetext{
*Correspondence: heyulong2003@163.com; wuyuehong2003@163.com ${ }^{1}$ College of Life Science, Zhejiang Sci-tech University, 928 Second Avenue, Xiasha Higher Education Zone, Hangzhou, China

Full list of author information is available at the end of the article
} 
(Continued from previous page)

Conclusions: Our results demonstrate that $M \varphi$ derived from hiPS perform the immunological function in response to Bacillus Calmette-Guérin infection by undergoing apoptosis, increasing the production of NO and expression of TNF-a. Thus, our study may help to overcome the limitations of research into certain rare diseases due to the lack of adequate supply of disease-specific primary cells.

Keywords: Human induced pluripotent stem cells, THP-1, Macrophages, BCG,

\section{Background}

Macrophages $(\mathrm{M} \phi)$ are one of the most important immune cells in the body and are distributed in most tissues and organs. These cells play a central role in the non-specific immune clearance of bacteria, viruses, fungal pathogens, and specific immune response antigen presentation and corresponding cytokine production [1]. While traditionally tissue-resident, $M \phi$ have been regarded as being continuously replenished from hematopoietic stem cells via the intermediate step of peripheral blood monocytes, this concept has recently been challenged [2].Thus, studies have recently demonstrated that substantial populations of $\mathrm{M} \phi$ are prenatally seeded and exhibit considerable longevity (months to years); in addition, these cells have, at least in part, self-renewal potential $[3,4]$.

Additionally, CD34+ hematopoietic stem cells, monocytes and early $\mathrm{T}$ lymphocytes, etc. [5] can be differentiated into macrophages under certain conditions. There are two main sources of human macrophages in vitro. One source is the cell lines derived from tumors, such as U937 and THP-1, and the other source is primary cells, such as peripheral blood mononuclear cells. The macrophages derived from the former have the potential for unlimited replication and play an important role in macrophage-related biology research [6, 7]. However, compared with primary macrophages, these immortalized cell lines are prone to abnormal genetic structure changes, leading to a lack of function, severely limiting their application in related research $[6,7]$. Macrophages derived from peripheral blood represent macrophages that cannot self-renew, and each study requires large amounts of blood from the donor and depends on the donor's physiological state and genes, etc., resulting in test results that are not representative.

Following the groundbreaking report by Takahashi and Yamanaka in 2006 [8], induced pluripotent stem cells (iPS) provide a new method and pathway for the screening of drugs and individual-specific treatments. Studies have demonstrated that humans, mice, pigs, sheep, guinea pigs, rhesus monkeys, and marmosets [9-13], and other species of various somatic cells, such as fibroblasts, peripheral blood cells, and amniotic fluid cells [14, 15], can be reprogrammed into iPS without the limitation of the donor age [16]. Now, human IPS (hiPS) can easily be generated by a number of reprogramming techniques and from various cell and tissue sources. Compared with traditional stem cell technology used in research, iPS technology not only avoids the ethical and moral limitations of stem cell research, but could also create an inexhaustible source of cells that could be used to derive the differentiated cells required for patient-specific therapy, such as macrophages, cardiomyocytes, neurons, and pancreatic beta cells $[17,18]$. However, successful iPSbased gene and cell therapy relies on the efficient differentiation of iPS into the desired cell types. Whereas substantial progress has been made to differentiate hiPS into defined mature hematopoietic cells, such as granulocytes, macrophages, erythrocytes, megakaryocytes or dendritic cells, lymphoid differentiation or the generation of long-term repopulating hematopoietic stem cells from humans remain hampered by the low quality and inefficient quantity of the output cells [2].

Studies have shown that iPS can be differentiated into immune cells under appropriate induction conditions [19-21]. The macrophages in immune cells are the most plastidic cells in the hematopoietic system and exist in all tissues and play many different roles in development [22], in vivo balance, tissue repair, immune response to pathogens $[23,24]$, and primary ovarian insufficiency [25]. Thus, the use of iPS-derived macrophages to establish a related disease model can further analyze the relationship between macrophages and disease. Although, many methods such as direct differentiation by the addition of different factors [26], the embryoid body (EB) formation method [27, 28], and co-culture with bone marrow stromal cells (OP9) [17] have been used for the differentiation of iPS into macrophages, the efficiency remains low, and the differentiation system remains unstable.

Furthermore, the generation of hiPS-derived macrophages focuses on the application of therapy or the pathogenesis of cancer [29, 30], Mendelian disease [31], Alzheimer's disease [30], HIV [32], Chlamydia trachomatis infections [33], chronic granulomatous disease [34], and Xlinked chronic granulomatous disease [35]. Unfortunately, many questions about the mechanisms of hiPS-derived macrophages in disease pathogenesis remain. Furthermore, macrophages show great promise in disease pathogenesis, particularly tuberculosis. Tuberculosis is a zoonotic infectious disease and a serious threat to human health. As the main host cells to invasive Mycobacterium tuberculosis (MTB), macrophages interact with MTB, playing a crucial 
role in the occurrence and development of tuberculosis. Studies of these interactions have confirmed a crucial role for these cells in the occurrence and development of tuberculosis. However, there is no information about hiPSderived macrophages in response to tuberculosis infection. In particular, their effects on tuberculosis infection, especially the immunological function in response to tuberculosis infection, have not been thoroughly investigated.

Thus, in the present study, we optimized the method used to generate these cells by using an EB-forming method combined with the addition of different factors to differentiate iPS into monocytes and subsequently mononuclear cells into macrophages. These investigations led to development of a stable experimental culture condition for human iPS differentiation. Using Western blot analysis, immunostaining and through a combination of flow cytometric analyses, we elucidated the immunological function of hiPS-derived macrophages (iPS-M $\phi$ ) in response to Bacillus Calmette-Guérinin (BCG) a similar manner to $\mathrm{M} \phi$ derived from human monocyte cells.

\section{Methods}

\section{Cell culture}

Human iPS (DYR0100 cells) and human embryonic stem (ES) (ZQ0271) were cultured under feeder-free culture conditions in chemically defined mTeSR1 medium (Stemcell Technologies, Vancouver, BC, Canada) on Matrigel (Corning, Corning, NY, USA)-coated dishes.

Human monocyte cells (THP-1) were cultured in RPMI 1640 medium supplemented with 10\% fetal bovine serum (FBS, Gibco, Waltham, MA, USA), $0.1 \mathrm{mg} / \mathrm{ml}$ penicillin and $0.05 \mathrm{mg} / \mathrm{ml}$ gentamicin.

\section{$M \varphi$ differentiation of iPS}

iPS-derived $M \phi$ and ES-derived $M \phi$ were generated using a modified version of a previously established protocol [31, 36-39]. The hiPS were gently digested with Accutase (Stemcell Technologies), and $2 \times 10^{6}$ cells were resuspended in Knockout-DMEM medium (KO-DMEM, Gibco) supplemented with 10\% Knockout-serum replacement (KSR, Gibco), 1\% Non-essential amino acids (NEAA, Gibco), $1 \mathrm{mM}$ L-Glutamine (Sigma-Aldrich, St. Louis, MO, USA), $50 \mu \mathrm{M} \beta$-mercaptoethanol ( $\beta$-ME, Solarbio, Beijing. China) and $10 \mu \mathrm{M}$ ROCK-inhibitor (Y-27632, Selleckchem, Houston, TX, USA) and cultured on 6-well ultralow attachment plates (Corning) for $24 \mathrm{~h}$. The medium was changed daily. After 8-11 days, EB were seeded onto gelatin-coated 24-well plates in DMEM (Gibco) medium supplemented with $10 \% \mathrm{FBS}, 1 \mathrm{mM}$ L-Glutamine, $50 \mu \mathrm{M}$ $\beta$-ME, $50 \mathrm{ng} / \mathrm{mL}$ human macrophage colony-stimulating factor (M-CSF) (PeproTech, Rocky Hill, NJ, USA), and 25 ng/mL human IL-3 (Gibco) at 6-8 EB per well. The medium was changed every 3 days. Continuous monocyte production was cultured for 17-19 days. Non-adherent monocytes were collected, and the other cells were continuously cultured. Non-adherent monocytes were cultured in RPMI 1640 medium supplemented with 10\% FBS, 100 $\mathrm{ng} / \mathrm{mL} \mathrm{M}-\mathrm{CSF}, 50 \mathrm{ng} / \mathrm{mL}$ interleukin (IL)-3, and $50 \mu \mathrm{M} \beta$ $\mathrm{ME}$ and identified for $\mathrm{M} \phi$ after 10 days.

\section{THP-1 derived macrophages (THP-1- M $\varphi$ )}

The THP-1 cells were trypsinized with $0.25 \%$ trypsin (Gibco) and centrifuged at $1000 \mathrm{rpm}$ for $5 \mathrm{~min}$. The cells were resuspended in RPMI 1640 medium supplemented with $100 \mathrm{ng} / \mathrm{mL}$ PMA (Beyotime, Beijing, China) and seeded into six-well plates at $10^{6}$ cells/well. After incubation for $24 \mathrm{~h}$, the medium was discarded, the cells were washed once with phosphate-buffered saline (PBS), and fresh RPMI 1640 medium was added to the cells.

\section{Giemsa stain assay}

iPS-M $\phi$ and human monocyte cell line THP-1 (THP-1$\mathrm{M} \phi)$ were fixed with $4 \%$ paraformaldehyde for $20 \mathrm{~min}$. Subsequently, the cells were washed twice with PBS and incubated at room temperature (RT) for 10-15 $\mathrm{min}$ in Giemsa solution (Solarbio). The Giemsa solution was discarded, followed by washing in PBS. The results of cell staining were observed by an inverted microscope.

\section{Phagocytosis assay}

iPS-M $\phi$ and THP-1-M $\phi$ were washed once in PBS. The Indian ink (Solarbio) was added to fresh medium at a ratio of 1:1000 and incubated with the cells for $1 \mathrm{~h}$ at $37^{\circ} \mathrm{C}$ in a $5 \% \mathrm{CO}_{2}$ incubator. The results of cell phagocytosis were observed and counted by an inverted microscope.

\section{Non-specific esterase stain (a-NAE method) assay}

The cells were fixed for approximately $10-15$ min in $\alpha$ NAE solution (Solarbio). Then, the cells were washed in PBS. The cells were added to the configured $\alpha$-NAE incubation solution, incubated for $1 \mathrm{~h}$ at $37^{\circ} \mathrm{C}$ in the dark, and subsequently washed with PBS. The cells were stained for approximately 5-15 min by methyl green dyeing solution, washed, and recorded by microscopic examination.

\section{Flow cytometry}

For the detection of surface markers and intracellular proteins, the cells were harvested after trypsin treatment and resuspended in ice-cold PBS. The following antibodies (Abs) conjugated with Annexin V-Fluorescein isothiocyanate (FITC) or PE were purchased from eBioscience (San Diego, CA, USA): anti-human CD11b FITC (11-0118), anti-human CD11b APC (17-0118), anti-human CD14 FITC (11-0149), anti-human CD40 PE (12-0401), anti-human CD68 PE (12-0689), and anti-mouse major histocompatibility complex (MHC) Class II (I-A) PE (12-5322). The cells were stained with the fluorochrome-conjugated Abs for $15 \mathrm{~min}$ and then 
Table 1 Primary antibodies used for immunostaining and FACS

\begin{tabular}{llll}
\hline Antibody & Company & Catalogue no. & Dilution \\
\hline Anti-CD11b antibody & Abcam & ab52478 & $1: 250$ \\
CD14 antibody & PeproTech & $17,000-1-A P$ & $1: 500$ \\
Anti-CD40 antibody & Abcam & ab224639 & $1: 100$ \\
CD68 antibody & PeproTech & $25,747-1-A P$ & $1: 500$ \\
Anti-MHCII antibody & Abcam & ab157210 & $1: 250$ \\
Alexa Fluor 555-labeled donkey anti-rabbit (H+L) & Beyotime & A0453 & $1: 500$ \\
Mouse IgG1 kappa isotype control, APC & eBioscience & $17-4714$ & $1: 20$ \\
Anti-human CD11b APC & eBioscience & $17-0118$ & $1: 20$ \\
Anti-human CD14 APC & eBioscience & $17-0149$ & $1: 20$ \\
Rat IgG2a K Iso control PE & eBioscience & $12-4321$ & $1: 20$ \\
Anti-human CD40 PE & eBioscience & $12-0401$ & $1: 40$ \\
Anti-human CD68 PE & eBioscience & $12-0689$ & $1: 20$ \\
Anti-mouse MHC Class II (I-A) PE & eBioscience & $12-5322$ & $1: 40$ \\
\hline
\end{tabular}

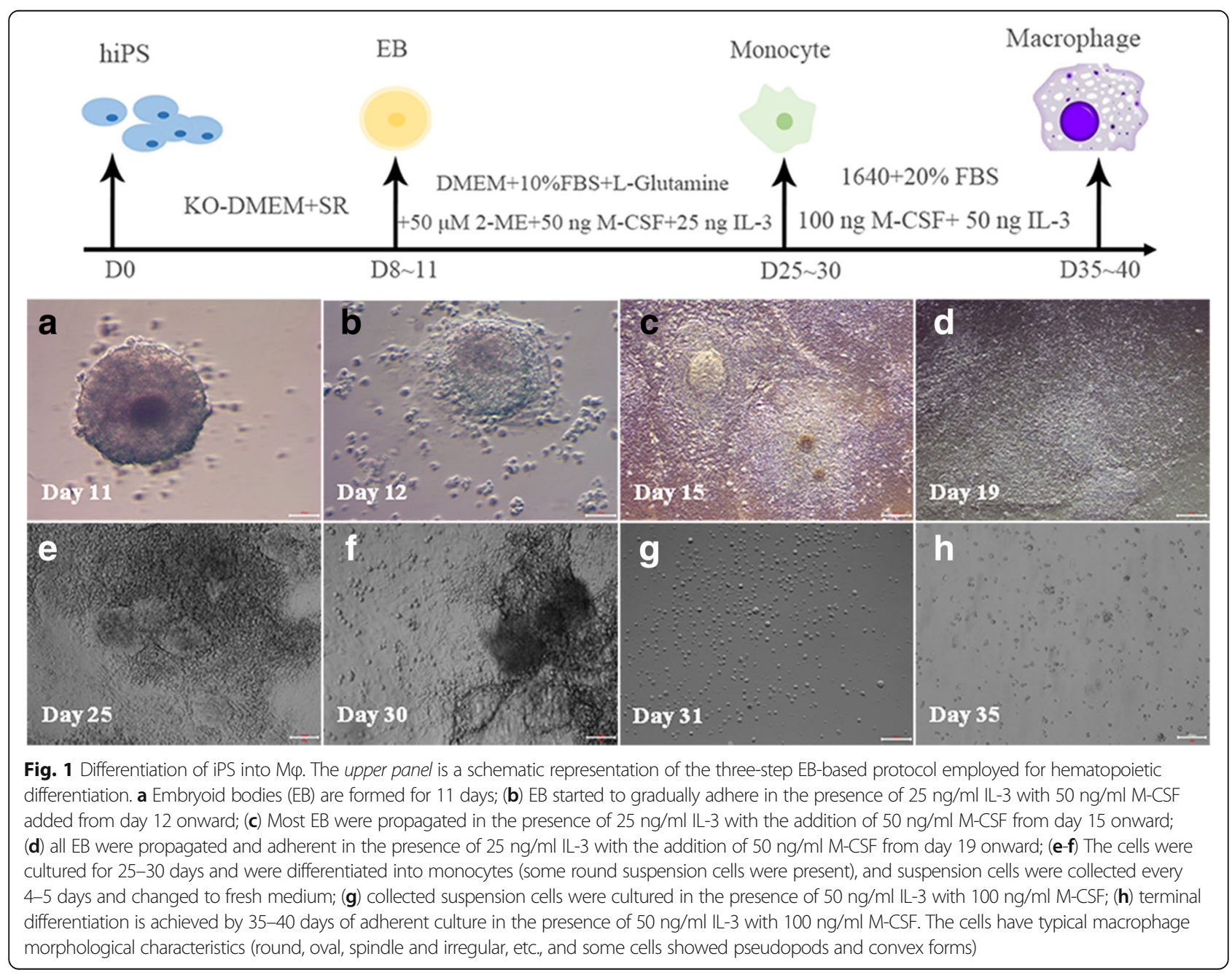




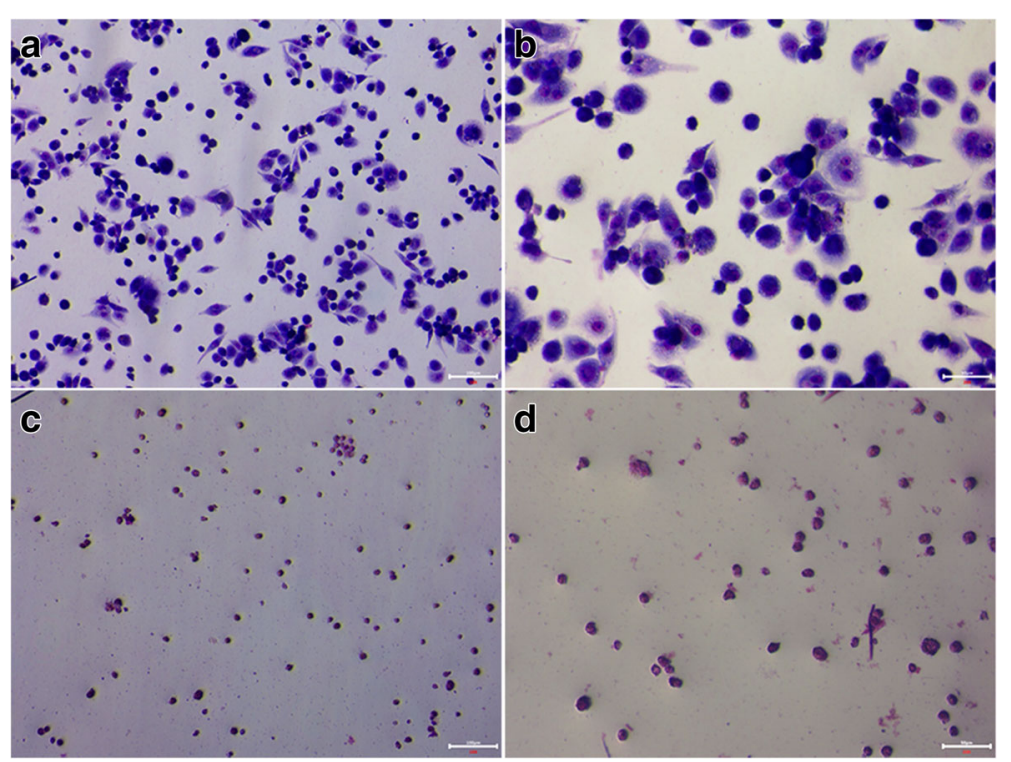

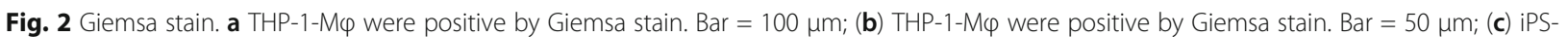
$\mathrm{M} \varphi$ were positive by Giemsa stain. Bar $=100 \mu \mathrm{m}$. $\mathbf{d}$ iPS-M $\varphi$ were positive by Giemsa stain. Bar $=50 \mu \mathrm{m}$

washed twice with PBS containing $2 \%$ FCS. The stained cells were recorded using a FACS Calibur platform (BD Biosciences, San Jose, CA, USA) and analyzed using FlowJo software (Tree Star, Ashland, OR, USA).

\section{Immunostaining}

For the detection of surface markers and intracellular proteins, the cells were washed twice with phosphatebuffered saline (PBS) and fixed in $4 \%$ paraformaldehyde in $0.1 \mathrm{M}$ phosphate buffer ( $\mathrm{pH} 7.4$ ) for $10 \mathrm{~min}$. The cells were washed three times with PBS, and blocked for at least 30 min with $1 \%$ BSA, $22.52 \mathrm{mg} / \mathrm{ml}$ glycine in PBST (PBS $+0.1 \%$ Tween 20$)$ at room temperature. They were then incubated at $4{ }^{\circ} \mathrm{C}$ overnight with the following antibodies: rabbit anti-CD11b (1:250; Abcam, Cambridge, MA USA), rabbit anti-CD14(1:500; PeproTech), rabbit anti-CD68 (1:500; PeproTech), rabbit anti-MHC class II $(1 ; 250 ;$ Abcam). The cells were washed three times with PBS and then incubated with the following secondary antibodies: Alexa Fluor 555-labeled donkey anti-rabbit IgG
$(\mathrm{H}+\mathrm{L})$ (1:500; Beyotime), nuclei were counterstained with 4',6-diamidino-2-phenylindole (DAPI) $(1 \mu \mathrm{g} / \mathrm{ml}$; Beyotime). The plates were examined by inverted fluorescence microscopy (Olympus, Tokyo, Japan) and the images were processed using the Adobe Photoshop software (Adobe, San Jose, CA, USA). The antibody details are listed in Table 1.

\section{BCG infection}

iPS-M $\phi$ and THP-1-M $\phi\left(1 \times 10^{6}\right.$ cells/well $)$ were infected with $1 \times 10^{7} \mathrm{CFU}$ of the BCG (http://www.shanghaishengwu.com). The culture systems were maintained according to the conditions described above. After $24 \mathrm{~h}$, the supernatants and cells were collected separately for measurement. Untreated cells were used as controls.

\section{Apoptosis assay by flow cytometry}

Apoptosis was performed by using a modified version of a previously established protocol [40]. Briefly, the cells were subsequently dissociated into single cells by trypsin, and apoptosis was measured according to the manufacturer's

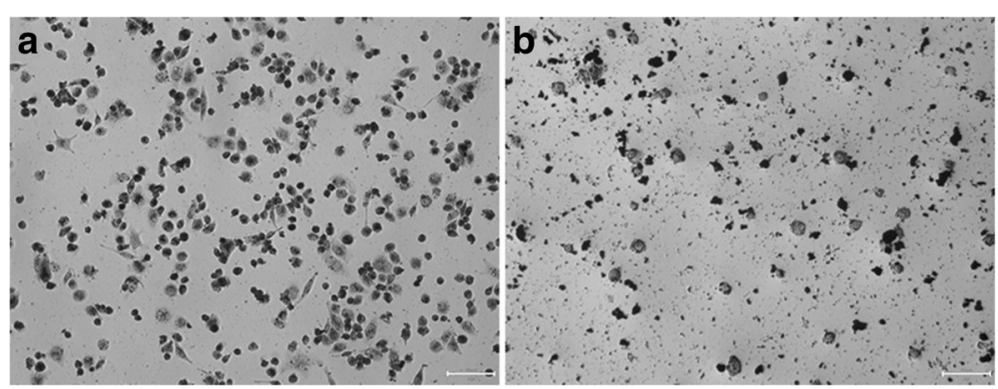

Fig. 3 a-NAE stain. a THP-1-M $\varphi$ were positive by a-NAE stain. Bar $=50 \mu \mathrm{m}$; (b) iPS-M $\varphi$ were positive by a-NAE stain. Bar $=50 \mu \mathrm{m}$ 


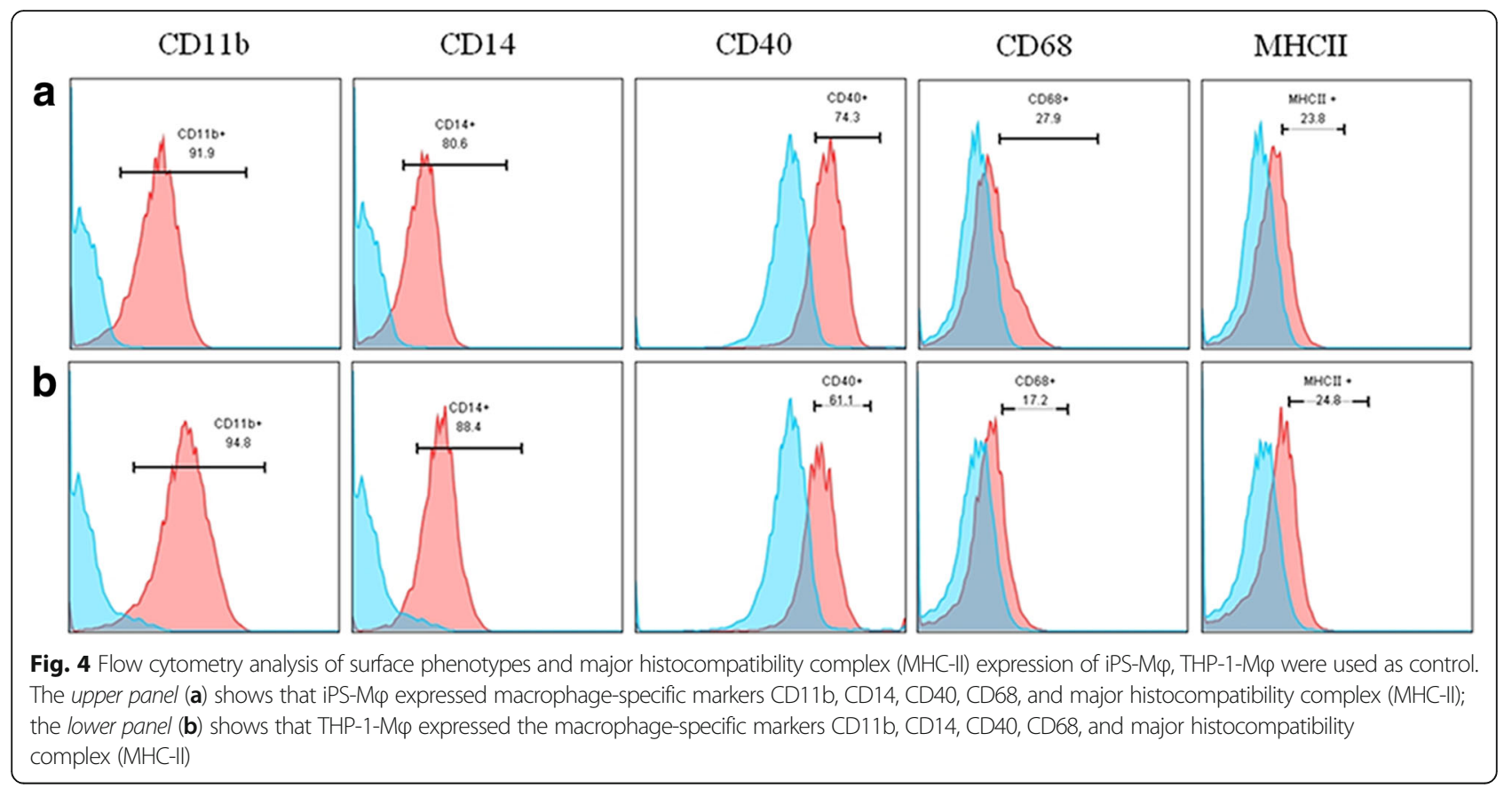

instructions with the FITC Annexin V Apoptosis Detection Kit (BD Biosciences).The samples were detected by using flow cytometry.

\section{NO concentration detection}

The supernatant of BCG-treated iPS-M $\phi$ and THP-1-M $\phi$ were collected separately, and the concentration of nitric oxide (NO) was determined by using the Griess Reagent System (Promega, Madison, WI, USA) according to the manufacturer's instructions. Different concentrations of gradient nitrite standard solution were prepared. To generate the nitrite standard reference curve, the absorbance value of the nitrite standard solution was measured by a standard microplate reader at $540 \mathrm{~nm}$. The absorbance value of the samples was measured, and the concentration was calculated according to the nitrite standard reference curve.

\section{Tumor necrosis factor alpha (TNF-a) assay}

The supernatant of BCG-treated iPS-M $\phi$ and THP-1-M $\phi$ was collected, according to instructions of the mouse TNF- $\alpha$ ELISA Kit (R\&D Systems, Minneapolis, MI, USA). The standard and sample wells were added to the corresponding wells of a microelisa strip plate, followed by the addition of HRP-labeled antibody. Chromogen Solution A and Chromogen Solution B were added to wells after washing and incubated in the dark. Stop solution was added, and the absorbance was measured with a standard microplate reader at a $450 \mathrm{~nm}$ wavelength. After drawing the standard linear regression curve of standards, the sample concentration was calculated according to the curve equation.

\section{Western blot analysis}

Whole lysates of THP-1-M $\phi$ and iPS-M $\phi$ were extracted with a protein extraction kit according to the manufacturer's

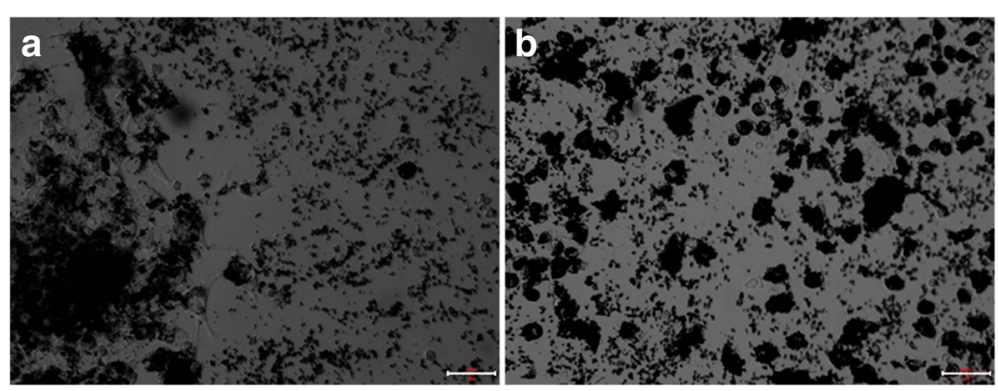

Fig. 5 Phagocytic function test. a iPS-M $\varphi$, Bar $=50 \mu \mathrm{m}$. b THP-1-M $\varphi$, Bar $=50 \mu \mathrm{m}$ 
instructions. Western blotting was performed following standard methods. Detailed antibody information is provided below: anti-Actin (Sigma-Aldrich, dilution ratio 1:1000), anti-TNF- $\alpha$ (Sigma-Aldrich, dilution ratio 1:1000), anti-apoptosis-related protein cysteine-3 (Caspase-3) (Sigma-Aldrich, dilution ratio 1:1000), and anti-B-cell lymphoma-2 (Bcl-2) (Sigma-Aldrich, dilution ratio 1:1000).

\section{Statistical analysis}

All statistical analyses were performed with SPSS version 13.0 software (SPSS, Inc., Chicago, IL, USA). Two-tailed unpaired Student's $t$ tests were used to evaluate differences between the control and treated groups. The data were given as the means of three experiments with $n=3$. The data are presented as the means \pm standard deviation. A value of $P<0.05$ represents a statistical difference, and $P<0.01$ represents a statistically significant difference.

\section{Results}

\section{Differentiation of hiPS into $M \varphi$}

Differentiation studies of hiPS into M $\phi$ have utilized an EBbased protocol. EB in suspension cultures were incubated in an orbital shaker, and to achieve terminal $\mathrm{M} \phi$ differentiation in secondary cultures, M-CSF and interleukin-3 (mIL-3) treatment was employed from days approximately 8-11 onward. The cells grew rapidly when EB were adherent cultured for approximately 15 days as shown in Fig. 1a-c). After approximately 8-11 days, the medium was replaced with monocyte differentiation medium employing M-CSF and interleukin-3 (mIL-3), and the cells showed irregular differentiation as shown in Fig. 1d. At 25-30 days, the cells tended towards monocyte differentiation, and the culture system showed round, oval cells (as shown in Fig. 1e-f). The suspension cells were collected for further differentiation as shown in Fig. 1g. When employing a higher concentration (twofold) of M-CSF and IL-3 in the cultures, the round and oval-shaped cells gradually increased at approximately day 35 , at which time the cells displayed plastic adherence and M $\phi$-typical morphology (> 95\% purity), displaying round, oval, spindle-shaped and irregularly shaped cells. Some cells were observed as convex pseudopods with other typical $\mathrm{M} \phi$ morphological characteristics at approximately day 35-40 upon bright-field microscopy, as shown in Fig. 1h.

\section{Functional characterization of hiPS-M $\varphi$}

The $\mathrm{M} \phi$ characteristics of almost all cells (> 95\% purity) were verified by typical, spread-out morphology with bright-field microscopy, and strong adherence to nontissue culture-treated plates as well as a classical $M \phi$ phenotype on Giemsa-stained cytospins resembling the THP-1-M $\phi$ used as controls. The stained cells had clear circular or irregular shapes, with pseudopods and protrusions. The cells had rich cytoplasm and a larger nucleus. The nucleus was located at one end of the cell and appeared darker. The morphology of the cells was horseshoe, round or irregular-shaped, as shown in Fig. 2. Additionally, iPS-M $\phi$ and THP-1-M $\phi$ were collected for identification by non-specific esterase stain. As shown in

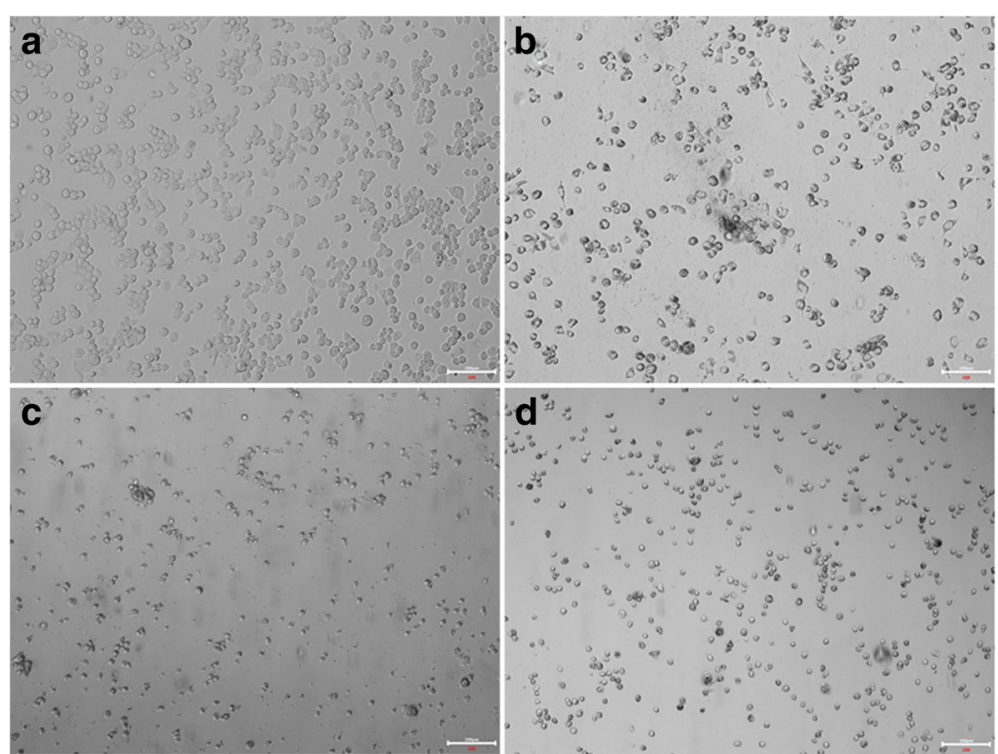

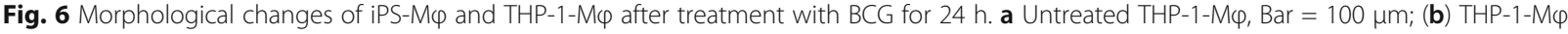

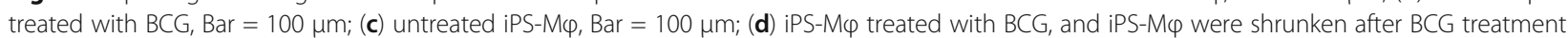
for $24 \mathrm{~h}$. Bar $=100 \mu \mathrm{m}$ 
Fig. 3, after the cells were stained with non-specific esterase, we observed black or brown-black dispersible particles in the cytoplasm, indicating that the cells contained $\alpha$-acetate esterase.

According to the antibody properties of the labeled anti-macrophage surface-specific antigen, the percentage of positive cells expressing CD11b, CD14, CD40, CD68, and MHC-II proteins were detected by flow cytometry at the corresponding wave lengths. The results showed that iPSC-M $\phi$ displayed the classical $M \phi$ marker. The percentage of cells expressing CD11b, CD14, CD40, CD68, and MHC-II surface antigens was 91.9\%, 80.6\%,
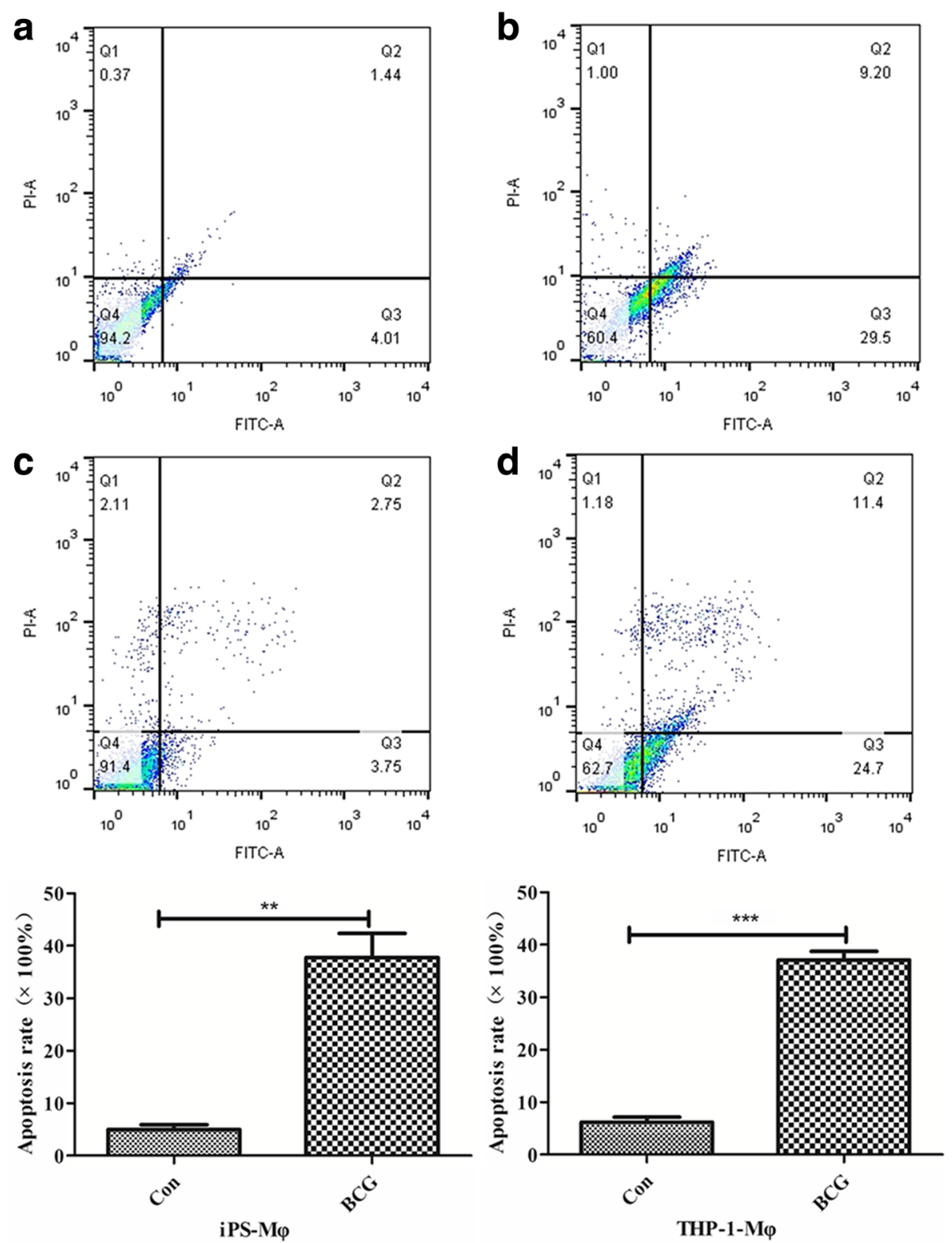

Fig. 7 BCG induced iPS-M $\varphi$ apoptosis by flow cytometric analysis of FITC Annexin $\mathrm{V}$ staining. iPS-M $\varphi$ were treated with BCG for $24 \mathrm{~h}$. FITC Annexin $\mathrm{V}$ and propidium iodide (PI)-positive cells were analyzed by flow cytometry. The majority $(37.77 \pm 7.94 \%, n=3)$ of treated iPS-M $\varphi$ became PI positive, FITC Annexin $V$ positive, or both FITC Annexin $V$ and PI positive. In contrast, only a small portion (4.97 $\pm 1.60 \%$ ) of untreated iPS-M $\varphi$ was PI positive, FITC Annexin $\vee$ positive, or both FITC Annexin $V$ and PI positive $(P<0.01)$. The portion of treated THP-1-M $\varphi$ was $37.1 \pm 2.84 \%$ and untreated THP-1-M $\varphi$ was $6.19 \pm 1.68 \%$. Statistical analysis was performed by using the $t$ test. A value of $P<0.01$ represents a statistically significant difference (Upper panel: upper right quadrant refers to late apoptosis; upper left quadrant refers to necrotic cells; lower left quadrant refers to viable cells; lower right quadrant refers to early apoptosis). TUNEL terminal deoxynucleotidyl transferase dUTP nick end labeling. The apoptosis analysis was repeated at least three times

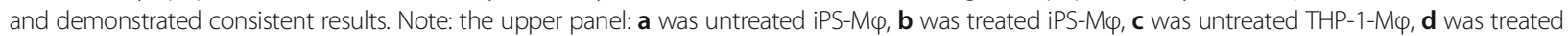
THP-1 -M ; the lower panel was the ratio of the apoptosis 
$74.3 \%, 27.9 \%$, and $23.8 \%$ in iPS-M $\phi$, respectively. By comparison, THP-1-M $\phi$ antigen expression was similar to iPS-M $\phi$, as shown in Fig. 4. Furthermore, immunostaining results showed that (Additional file 1: Figure S1, Additional file 2: Figure S2, Additional file 3: Figure S3, Additional file 4: Figure S4 and Additional file 5: Figure S5), the expression of $M \phi$ lineage markers CD11b, CD14, CD40, CD68, and MHC-II were all similar in iPSC-M $\phi$ and in THP-1-M $\phi$ as well as in hES-derived macrophages $(E S-M \phi)$. These results demonstrated that the induced and differentiated cells are macrophages.

The phagocytosis function of iPS-M $\phi$ was tested by the phagocytic ability of ink particles, and THP-1-M $\phi$ was used as a control. As shown in Fig. 5, a varying degree of ink particles was distributed throughout the cytoplasm, indicating that the cells exhibited phagocytic ability.

\section{Immunological function of $\mathrm{PSS}-\mathrm{M} \varphi$ in response to tuberculosis infection}

To determine whether iPS-M $\phi$ would show the same response to tuberculosis infection as THP-1- M treated iPS-M $\phi$ with BCG for $24 \mathrm{~h}$ and then observed the morphology of iPS-M $\phi$. The morphology of iPS-M $\phi$ was changed after BCG treatment for $24 \mathrm{~h}$. As shown in Fig. 6, iPS-M $\phi$ were shrunken, and some of the cells were ruptured, similar to THP-1-M $\phi$.

To further determine how iPS-M $\phi$ responded to tuberculosis challenge, iPS-M $\phi$ were treated with BCG for $24 \mathrm{~h}$, and the apoptosis rates were evaluated by using a FITC Annexin V Apoptosis Detection Kit. According to manufacturer instructions, the cells in late apoptosis or already dead cells are both FITC Annexin V and propidium iodide (PI) positive, whereas cells undergoing apoptosis are FITC Annexin V positive. iPS-M $\phi$ and THP-1- M $\phi$ were incubated with FITC Annexin V in a buffer containing PI and subsequently analyzed by flow cytometry. The apoptosis analysis was repeated at least three times and demonstrated consistent results. As shown in Fig. 7 , the majority (37.77 $\pm 7.94 \%, n=3)$ of treated iPS-M $\phi$ became PI positive, FITC Annexin V positive, or both FITC Annexin V and PI positive. In contrast, only a small portion $(4.97 \pm 1.60 \%)$ of untreated iPS-M $\phi$ was PI positive, FITC Annexin V

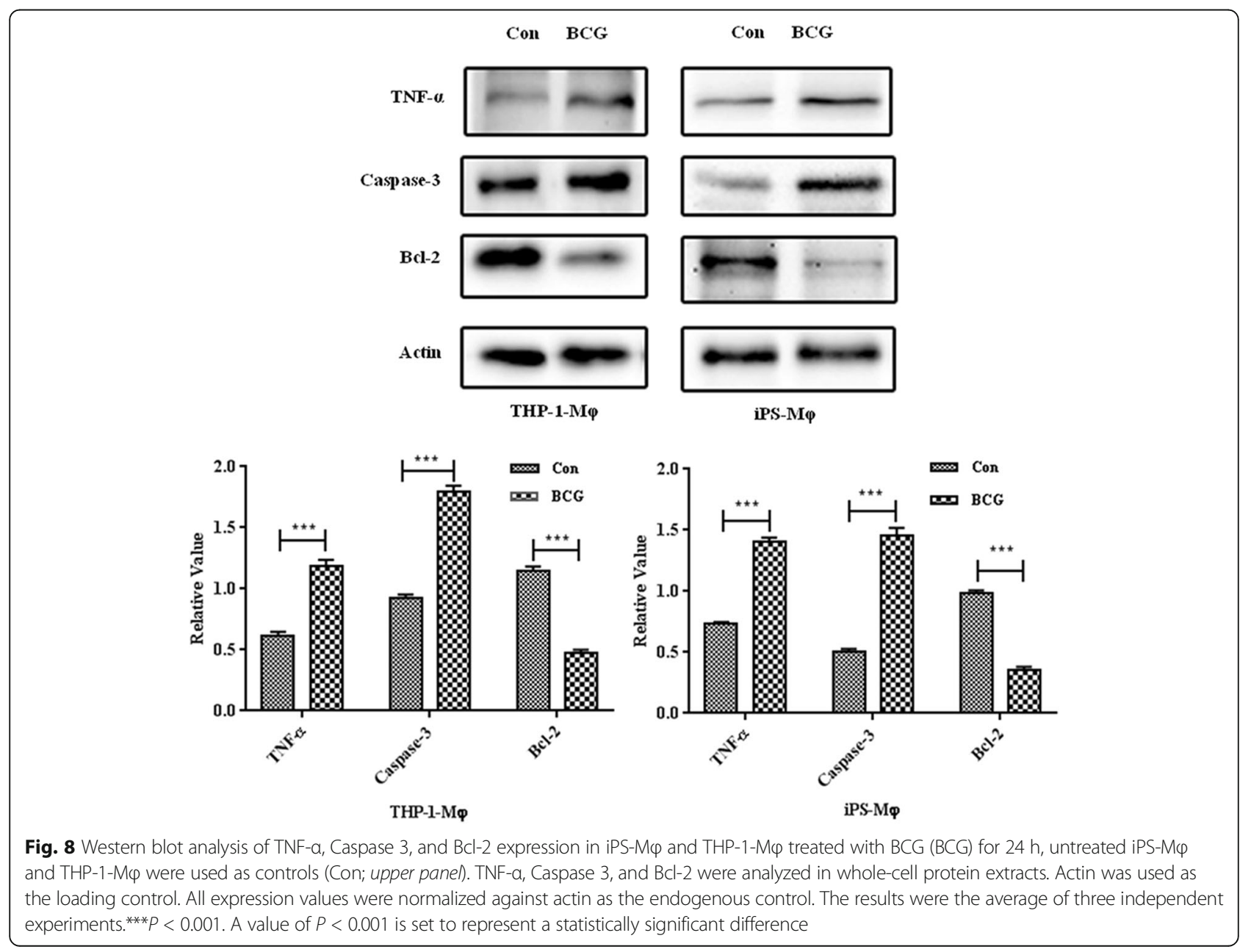


positive, or both FITC Annexin V and PI positive $(P<$ $0.01)$. Notably, the portion of treated THP-1-M $\phi$ was $37.1 \pm 2.84 \%$ and the portion of untreated THP-1-M $\phi$ was $6.19 \pm 1.68 \%$. Thus, iPS-M $\phi$ performed similar to THP-1-M $\phi$ in response to BCG.

To investigate how apoptosis is initiated and determine the cytokine involved profile, we measured the protein expression levels of Bcl-2, Caspase-3, and TNF- $\alpha$ after iPS$\mathrm{M} \phi$ were cultured in the presence of BCG for $24 \mathrm{~h}$. As shown in Fig. 8, the expression levels of TNF- $\alpha$ and Caspase-3 in iPS-M $\phi$ and THP-1-M $\phi$ were increased after BCG treatment compared with the untreated group; however, the level of Bcl-2 was decreased $(P<0.001)$.

Because Caspase- 3 is a central caspase in the proapoptotic cascade and plays a key role in various forms of apoptosis, the Caspase-3 activity of iPS-M $\phi$ and THP-1-M $\phi$ was therefore determined by the Caspase-3 Activity Assay Kit. The results showed that the BCG treatment increased Caspase- 3 activity in iPS-M $\phi$, similar to THP-1-M $\phi$ as shown in Fig. 9.

We further examined the cytokine profiles in both iPS-M $\phi$ and THP- 1 cells after infection with BCG for 24 h. The content of NO in different concentration standards was measured by using the Griess method. The results are shown in Fig. 10. Compared with the control group, the production of NO in BCG-treated iPS-M $\phi$ and THP-1-M $\phi$ was significantly increased $(P<0.001)$.

The production of TNF- $\alpha$ was measured by using an ELISA Kit. As shown in Fig. 11, the expression of TNF$\alpha$ protein in iPS-M $\phi$ and THP-1-M $\phi$ was significantly increased after BCG treatment $(P<0.001)$.

\section{Discussion}

In an ideal world, nearly any cell type necessary for the analysis of host-pathogen interactions or therapy in vitro could be generated from stem cells [41]. Among most stem cell types, hiPS-based gene and cell therapy holds great promise for innovative treatment strategies in regenerative medicine. The concepts most commonly envisioned in this context postulate the generation of patient-derived iPS, which, after appropriate differentiation, will be transplanted to the patient as individualspecific treatments or for the screening of drugs (as shown in Fig. 12) [42]. The efficient differentiation of iPS has previously been established for a number of different tissues and organ systems, including the cells of the hematopoietic system [17]. However, iPS-based gene and cell therapy approaches employing patient-
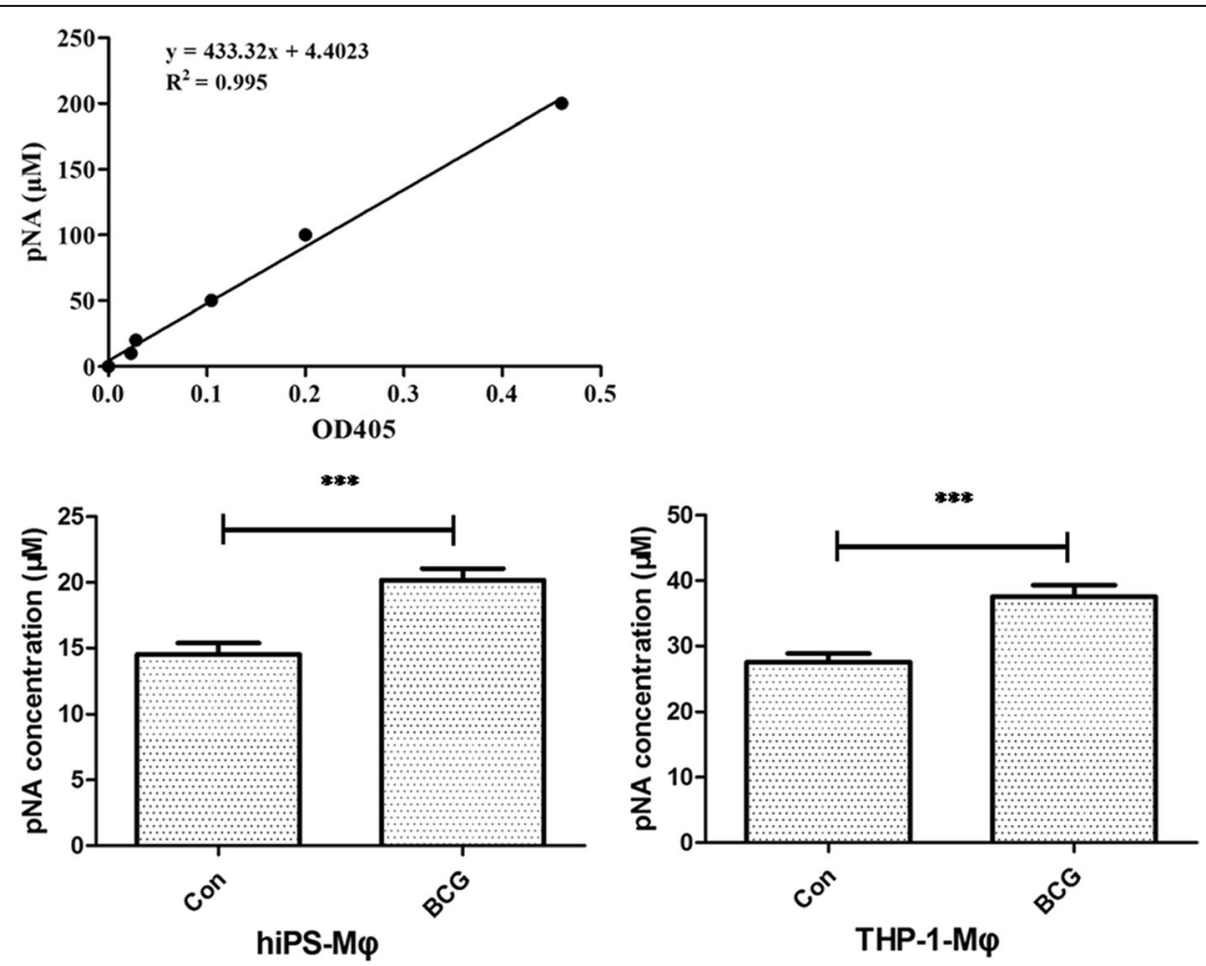

Fig. 9 BCG treatment increased the Caspase-3 activity of IPS-M $\varphi$. IPS-M $\varphi$ and THP-1-M $\varphi$ were treated by BCG for 24 h. The upper panel illustrates the determination of the standard curve of Caspase-3, whereas the lower panel documents Caspase-3 activity. The majority $(20.17 \pm 0.8696 \mu \mathrm{M})$ of BCG-treated PPS-M $\varphi$ (BCG) became p-nitroaniline (pNA) positive. In contrast, only a small portion (14.52 \pm 0.8696 uM) of iPS-M $\varphi$ untreated with BCG (Con) was pNA positive $(P<0.001)$.The majority $(37.57 \pm 1.739 \mathrm{uM})$ of BCG-treated THP-1-M $\varphi(B C G)$ became pNA positive. In contrast, only a small portion ( $27.57 \pm 1.304 \mathrm{UM}$ ) of iPS-M $\varphi$ untreated with BCG (Con) was pNA positive $(P<0.001)$.Statistical analysis was performed by using a $t$ test. A value of $P<0.001$ represents a statistically significant difference 

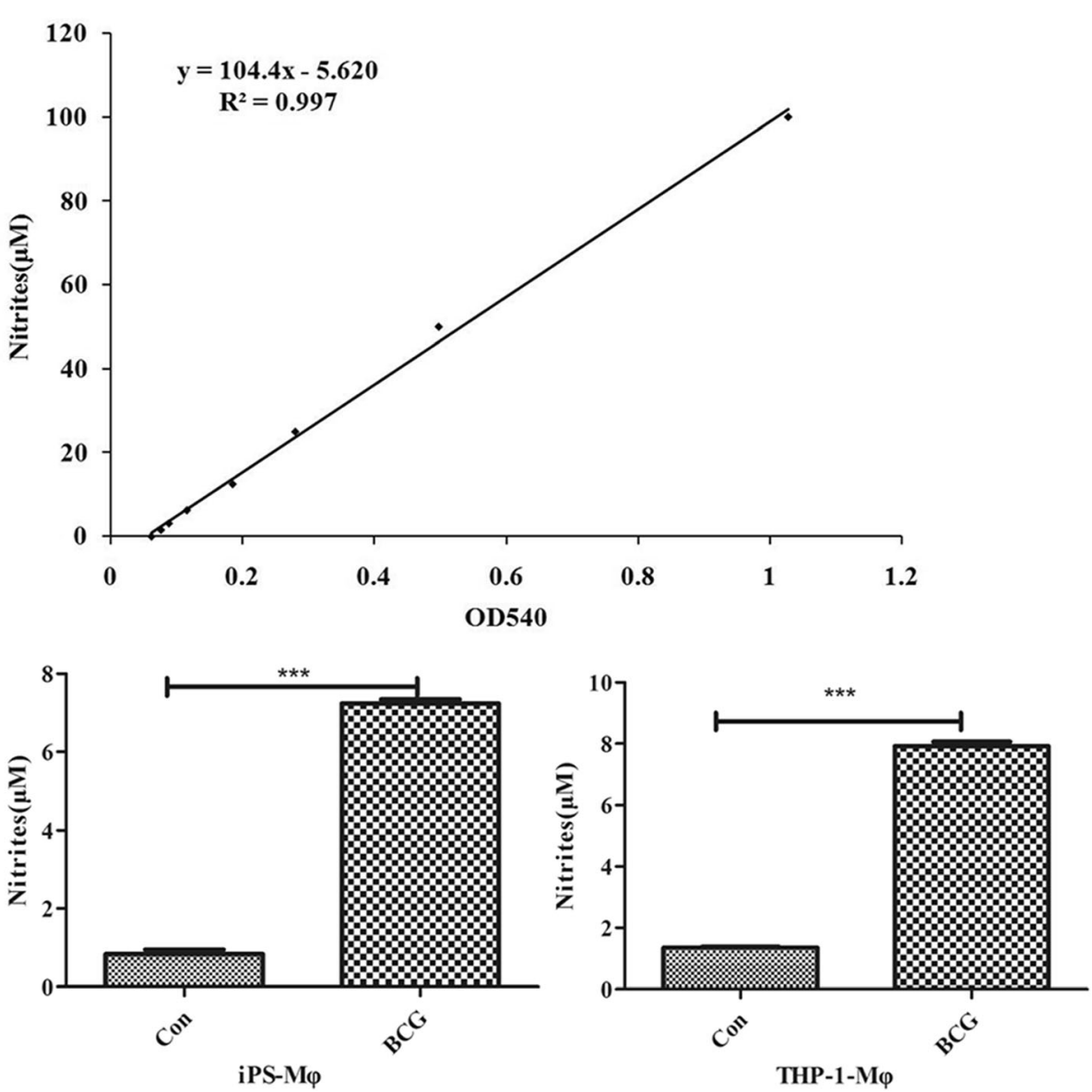

Fig. 10 Effects of BCG on the production of NO in IPS-M $\varphi$ and THP-1-M $\varphi$. The upper panel was the standard curve of NO. The production of NO in BCG-treated iPS-M $\varphi$ and THP-1-M $\varphi$ was significantly increased $(P<0.001)$

specific iPS rely on the efficient robustness and reproducibility of the differentiation of target cells.

Among the multiple lineages of differentiated cells derived from hiPS, macrophages hold great promise in disease pathogenesis or therapy, such as cancer [29, 30], Mendelian disease [31], Alzheimer's disease [30], HIV [32], Chlamydia trachomatis pathogenesis [33], chronic granulomatous disease [34], and X-linked chronic granulomatous diseases [35], particularly tuberculosis. Despite substantial appreciation for the dual function of macrophages in innate immunity and lipid metabolism, understanding human macrophage biology has been hampered by the lack of reliable and scalable models for cellular and genetic studies. In the present study, we generated macrophages derived from hiPS. These iPS-derived macrophages exhibited the typical morphology of macrophages and were tested for the expression of cell surface markers (e.g., CD11b, CD14, CD40, CD68) and major histocompatibility complex (MHC-II) and phagocytosis of foreign particles. The iPS-derived macrophages were not distinguishable from THP-1-derived macrophages. We also figured out that based on the same differentiation method, human ES could differentiate into macrophage. Moreover, human ES derived-macrophages expressed cell surface markers (CD11b, CD14, CD40, CD68) and major histocompatibility complex (MHC-II), which were all similar to iPSC-M $\phi$.

Tuberculosis is a zoonotic infectious disease that poses a serious threat to human health. As the main host cells to invasive MTB, macrophages interact with MTB and, therefore, play a crucial role in the occurrence and development of tuberculosis. Studies of their interactions have confirmed that these cells indeed play a crucial role in the occurrence and development of tuberculosis.

Bacteria and other pathogens are recognized via their pathogen-associated molecular patterns, which initiate a signaling cascade that results in phagocytosis of pathogens and upregulation of a pro-inflammatory response. Macrophages kill the infected MTB by direct phagocytosis, autophagy, apoptosis, and secretion of inflammatory factors and free radicals. MTB infection results in the activation of macrophages that secrete a series of inflammatory factors, such as TNF- $\alpha$, IL-6, etc. TNF- $\alpha$ is an important inflammatory factor that regulates cellular non-specific immunity to MTB and cell apoptosis. 

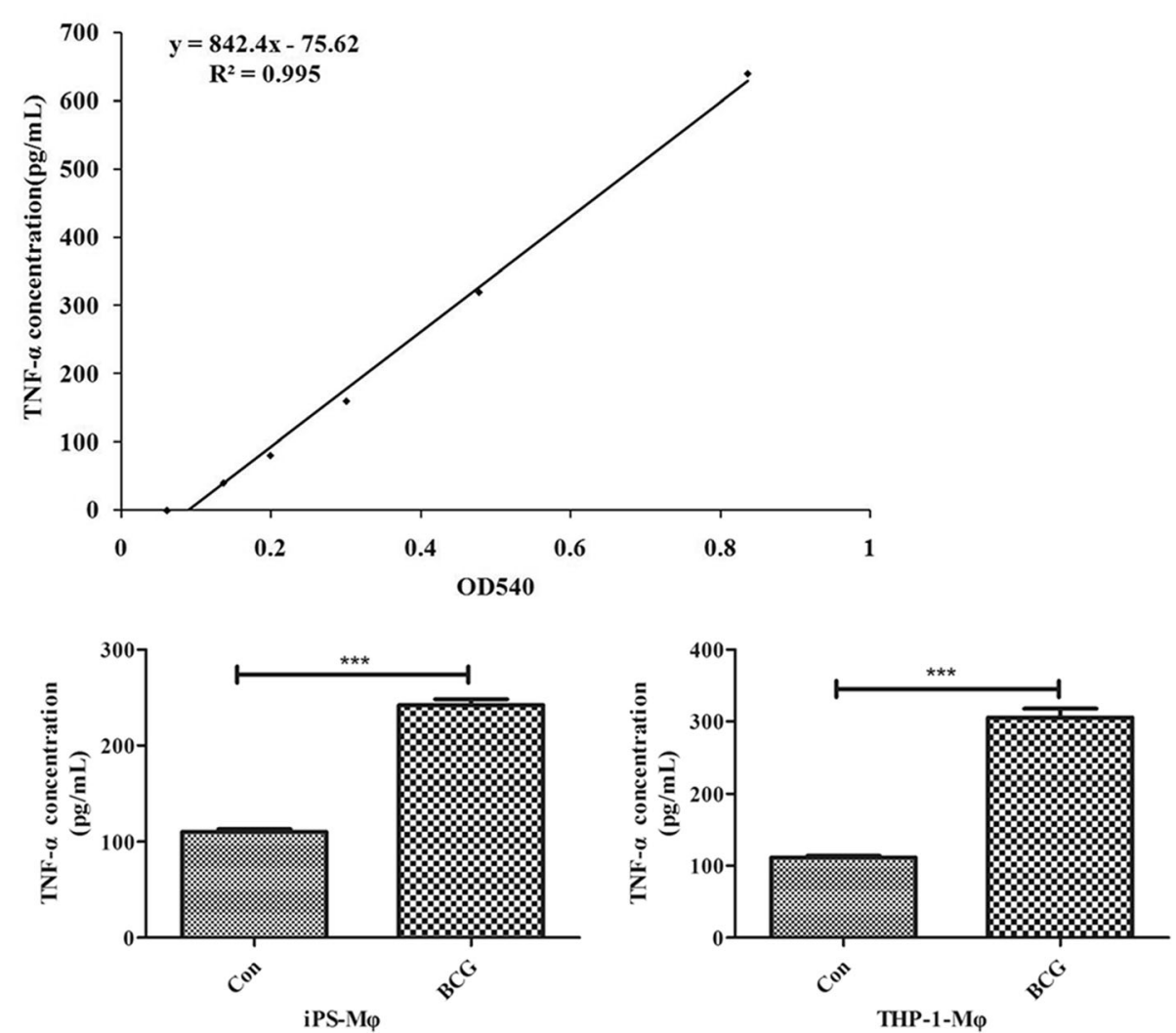

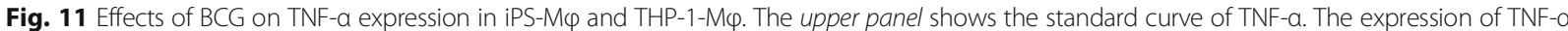
protein in $\mathrm{PSS}-\mathrm{M} \varphi$ and THP-1-M $\varphi$ was significantly increased after BCG treatment $(P<0.001)$

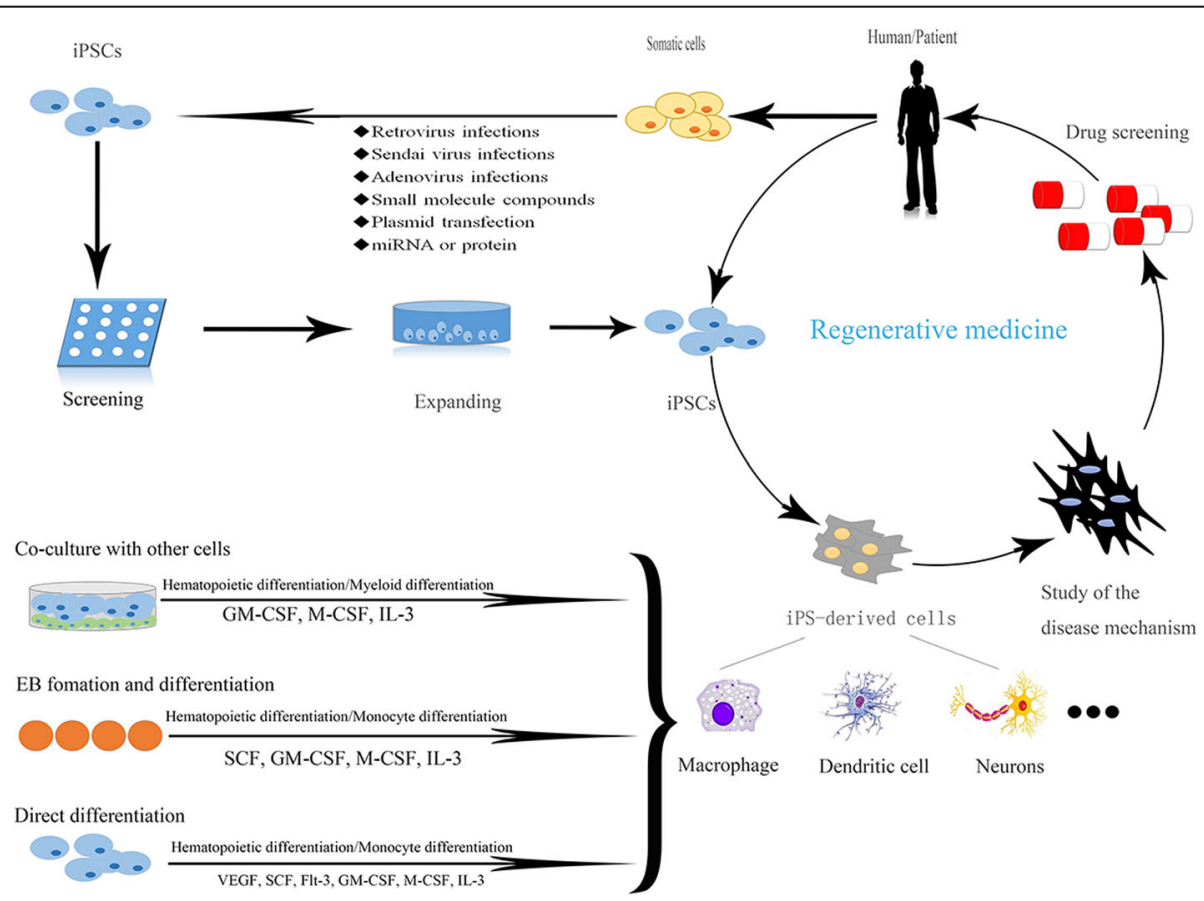

Fig. 12 Potential application of iPS in regenerative medicine and differentiation into macrophages 
Activated macrophages kill MTB by catalyzing NO. Moreover, MTB regulate cell apoptosis mainly via the Caspase family, Bcl family, TNF- $\alpha, \mathrm{NO}$, and other pathways. Therefore, to further elucidate the immunological function of hiPS-derived macrophages in response to tuberculosis infection, we examined the effects of BCG on iPS-M $\phi$. Our results demonstrate that in response to BCG infection, iPS-M $\phi$ undergo apoptosis and increase the production of NO and expression of TNF- $\alpha$. Additionally, our results demonstrate that apoptosis was induced by the suppressed expression of $\mathrm{Bcl}-2$ and enhanced activity of Caspase-3. The iPS-derived macrophages were not distinguishable from THP-1-derived macrophages in response to tuberculosis infection. The most notable cytokines produced by macrophages associated with this pro-inflammatory state in $\mathrm{TB}$ are tumor necrosis factor (TNF) [43]. Our results are consistent with those of a previous study [43]. Therefore, we have provided evidence for the use of human iPSderived macrophages to study the complex interplay between the host and pathogen after tuberculosis infection.

\section{Conclusions}

In conclusion, human iPS-derived macrophages respond to BCG in a similar manner to macrophages derived from human monocytes. Importantly, the identification host factors potentially involved in macrophage-mycobacterium tuberculosis interaction. Thus, we have provided evidence that we can use the human iPS-M $\phi$ in response to the Bacillus Calmette-Guérin infection model to study the complex interplay between the host and the pathogen.

\section{Additional files}

Additional file 1: Figure S1. Immunofluorescence images showing the positive expression of $\mathrm{M} \varphi$ lineage markers CD11b in $\mathrm{PS}-\mathrm{M} \varphi(\mathrm{A}), \mathrm{THP}-1-\mathrm{M} \varphi(\mathrm{B})$

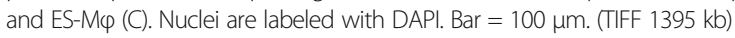

Additional file 2: Figure S2. Immunofluorescence images showing the

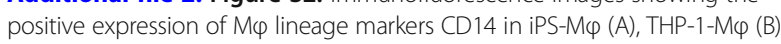
and ES-M $\varphi$ (C). Nuclei are labeled with DAPI. Bar = $100 \mu \mathrm{m}$. (TIFF $1337 \mathrm{~kb}$ )

Additional file 3: Figure S3. Immunofluorescence images showing the

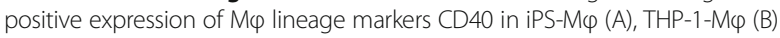

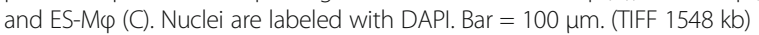

Additional file 4: Figure S4. Immunofluorescence images showing the

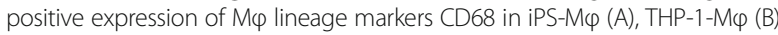
and ES-M $\varphi$ (C). Nuclei are labeled with DAPI. Bar = $100 \mu \mathrm{m}$. (TIFF 1431 kb)

Additional file 5: Figure S5. Immunofluorescence images showing the

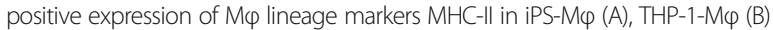

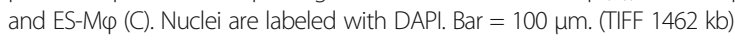

\section{Abbreviations}

Abs: Antibodies; BCG: Bacillus Calmette-Guérin; Bcl-2: B-cell lymphoma-2; Caspase-3: Apoptosis-related protein cysteine-3; DAPI: 4',6-diamidino-2-phenylindole; EB: Embryoid body; ES-M $\varphi$ : hES-derived macrophages; FBS: Fetal bovine serum; FITC: Annexin V-Fluorescein isothiocyanate; hES: Human embryonic stem cells; IL: Interleukin; iPS: Induced pluripotent stem cells; iPS-M $\varphi$ : hiPS-derived macrophages; M-CSF: Macrophage colony-stimulating factor; MHC-II: Major

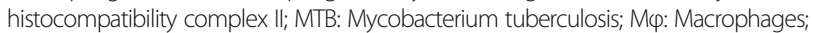
NO: Nitric oxide; OP9: Bone marrow stromal cells; PBS: Phosphate-buffered saline;
PI: Propidium iodide; pNA: p-nitroaniline; THP-1-M $\varphi$ : Human monocyte cell line THP-1; TNF-a: Tumor necrosis factor alpha; a-NAE: Nonspecific esterase staining

\section{Acknowledgements}

We thank Stem Cell Bank, Chinese Academy of Sciences for kindly providing human iPS, Shanghai Zhong Qiao Xin Zhou Biotechnology Co. Ltd. For kindly providing human ES and Dr. Caiyun Fu, Zhejiang Sci-Tech University for kindly providing human monocyte cells (THP-1).

\section{Funding}

This work was supported by grants from the China National Natural Science Foundation (Nos. 31201867 and 31260287) and the Zhejiang Province Natural Science Foundation (Nos. LY17C120001).

\section{Availability of data and materials}

Not applicable.

\section{Authors' contributions}

$\mathrm{DH}, \mathrm{JD}, \mathrm{OL}$, and $\mathrm{QH}$ participated in the experiments of human iPS differentiation and cell culture. JD performed the immunostaining experiment. MK, $M Z$, $L L$, and WBO participated in the molecular biology experiments. YH contributed to data analysis and manuscript writing. YH and YW conceived the idea, designed the experiments, and provided administrative support and final approval of manuscript. All authors read and approved the final manuscript.

Ethics approval and consent to participate

Not applicable.

\section{Consent for publication}

Not applicable.

\section{Competing interests}

All authors declare that their participation in the study did not involve factual or potential competing interests.

\section{Publisher's Note}

Springer Nature remains neutral with regard to jurisdictional claims in published maps and institutional affiliations.

\section{Author details}

${ }^{1}$ College of Life Science, Zhejiang Sci-tech University, 928 Second Avenue, Xiasha Higher Education Zone, Hangzhou, China. ${ }^{2}$ Zhejiang Provincial Key Laboratory of Silkworm Bioreactor and Biomedicine, Hangzhou 310018, China.

Received: 30 November 2017 Revised: 30 January 2018 Accepted: 7 February 2018 Published online: 26 February 2018

\section{References}

1. Stout RD, Suttles J. Functional plasticity of macrophages: reversible adaptation to changing microenvironments. J Leukoc Biol. 2004;76:509-13.

2. Mucci A, Kunkiel J, Suzuki T, Brennig S, Glage S, Kuhnel MP, et al. Murine iPSC-derived macrophages as a tool for disease modeling of hereditary pulmonary alveolar proteinosis due to Csf2rb deficiency. Stem Cell Rep. 2016:7:292-305.

3. Gomez Perdiguero E, Klapproth K, Schulz C, Busch K, Azzoni E, Crozet L, et al. Tissue-resident macrophages originate from yolk-sac-derived erythromyeloid progenitors. Nature. 2015;518:547-51.

4. Hashimoto D, Chow A, Noizat C, Teo P, Beasley MB, Leboeuf M, et al. Tissueresident macrophages self-maintain locally throughout adult life with minimal contribution from circulating monocytes. Immunity. 2013;38:792-804.

5. Esashi E, Ito H, Ishihara K, Hirano T, Koyasu S, Miyajima A. Development of CD4+ macrophages from intrathymic T cell progenitors is induced by thymic epithelial cells. J Immunol. 2004;173:4360-7.

6. Adati N, Huang MC, Suzuki T, Suzuki H, Kojima T. High-resolution analysis of aberrant regions in autosomal chromosomes in human leukemia THP-1 cell line. BMC Res Notes. 2009;2:153.

7. Schildberger A, Rossmanith E, Eichhorn T, Strassl K, Weber V. Monocytes, peripheral blood mononuclear cells, and THP-1 cells exhibit different cytokine expression patterns following stimulation with lipopolysaccharide. Mediators Inflamm. 2013;2013:697972. 
8. Takahashi K, Yamanaka S. Induction of pluripotent stem cells from mouse embryonic and adult fibroblast cultures by defined factors. Cell. 2006;126: 663-76

9. Bao L, He L, Chen J, Wu Z, Liao J, Rao L, et al. Reprogramming of ovine adult fibroblasts to pluripotency via drug-inducible expression of defined factors. Cell Res. 2011:21:600-8.

10. Ezashi T, Telugu BP, Alexenko AP, Sachdev S, Sinha S, Roberts RM. Derivation of induced pluripotent stem cells from pig somatic cells. Proc Natl Acad Sci U S A. 2009;106:10993-8.

11. Liao J, Cui C, Chen S, Ren J, Chen J, Gao Y, et al. Generation of induced pluripotent stem cell lines from adult rat cells. Cell Stem Cell. 2009;4:11-5.

12. Wu Y, Li O, He C, Li Y, Li M, LiU XL, et al. Generation and characterization of induced pluripotent stem cells from guinea pig fetal fibroblasts. Mol Med Rep. 2017;15:3690-8.

13. Wu Y, Zhang Y, Mishra A, Tardif SD, Hornsby PJ. Generation of induced pluripotent stem cells from newborn marmoset skin fibroblasts. Stem Cell Res. 2010:4:180-8.

14. Staerk J, Dawlaty MM, Gao Q, Maetzel D, Hanna J, Sommer CA, et al. Reprogramming of human peripheral blood cells to induced pluripotent stem cells. Cell Stem Cell. 2010;7:20-4.

15. Li C, Zhou J, Shi G, Ma Y, Yang Y, Gu J, et al. Pluripotency can be rapidly and efficiently induced in human amniotic fluid-derived cells. Hum Mol Genet. 2009:18:4340-9.

16. Dimos JT, Rodolfa KT, Niakan KK, Weisenthal LM, Mitsumoto H, Chung W, et al. Induced pluripotent stem cells generated from patients with ALS can be differentiated into motor neurons. Science. 2008;321:1218-21.

17. Senju S, Haruta M, Matsunaga Y, Fukushima S, Ikeda T, Takahashi K, et al. Characterization of dendritic cells and macrophages generated by directed differentiation from mouse induced pluripotent stem cells. Stem Cells. 2009, 27:1021-31.

18. Takahashi K, Tanabe K, Ohnuki M, Narita M, Ichisaka T, Tomoda K, et al. Induction of pluripotent stem cells from adult human fibroblasts by defined factors. Cell. 2007;131:861-72

19. Ahfeldt T, Schinzel RT, Lee YK, Hendrickson D, Kaplan A, Lum DH, et al. Programming human pluripotent stem cells into white and brown adipocytes. Nat Cell Biol. 2012:14:209-19.

20. Lapillonne H, Kobari L, Mazurier C, Tropel P, Giarratana MC, Zanella-Cleon I, et al. Red blood cell generation from human induced pluripotent stem cells: perspectives for transfusion medicine. Haematologica. 2010;95:1651-9.

21. Sivalingam J, Lam AT, Chen HY, Yang BX, Chen AK, Reuveny S, et al. Superior red blood cell generation from human pluripotent stem cells through a novel microcarrier-based embryoid body platform. Tissue Eng Part C Methods. 2016:22:765-80.

22. Lee CL, Guo Y, So KH, Vijayan M, Guo Y, Wong VH, et al. Soluble human leukocyte antigen $\mathrm{G} 5$ polarizes differentiation of macrophages toward a decidual macrophage-like phenotype. Hum Reprod. 2015;30:2263-74.

23. Chawla A, Nguyen KD, Goh YP. Macrophage-mediated inflammation in metabolic disease. Nat Rev Immunol. 2011;11:738-49.

24. Epelman S, Lavine KJ, Randolph GJ. Origin and functions of tissue macrophages. Immunity. 2014;41:21-35.

25. Leng L, Tan Y, Gong F, Hu L, Ouyang Q, Zhao Y, et al. Differentiation of primordial germ cells from induced pluripotent stem cells of primary ovarian insufficiency. Hum Reprod. 2015;30:737-48.

26. Yanagimachi MD, Niwa A, Tanaka T, Honda-Ozaki F, Nishimoto S, Murata Y, et al. Robust and highly-efficient differentiation of functional monocytic cells from human pluripotent stem cells under serum- and feeder cell-free conditions. PLoS One. 2013:8:e59243.

27. Panicker LM, Miller D, Awad O, Bose V, Lun Y, Park TS, et al. Gaucher iPSCderived macrophages produce elevated levels of inflammatory mediators and serve as a new platform for therapeutic development. Stem Cells. 2014; 32:2338-49.

28. Zhan X, Dravid G, Ye Z, Hammond H, Shamblott M, Gearhart J, et al. Functional antigen-presenting leucocytes derived from human embryonic stem cells in vitro. Lancet. 2004;364:163-71.

29. Senju S, Koba C, Haruta M, Matsunaga Y, Matsumura K, Haga E, et al. Application of iPS cell-derived macrophages to cancer therapy. Oncoimmunology. 2014;3:e27927

30. Senju S, Haruta M, Matsumura K, Matsunaga Y, Fukushima S, Ikeda T, et al. Generation of dendritic cells and macrophages from human induced pluripotent stem cells aiming at cell therapy. Gene Ther. 2011:18:874-83.
31. Zhang $H$, Xue C, Shah R, Bermingham K, Hinkle CC, Li W, et al. Functional analysis and transcriptomic profiling of iPSC-derived macrophages and their application in modeling Mendelian disease. Circ Res. 2015;117:17-28.

32. Kambal A, Mitchell G, Cary W, Gruenloh W, Jung Y, Kalomoiris S, et al. Generation of HIV-1 resistant and functional macrophages from hematopoietic stem cell-derived induced pluripotent stem cells. Mol Ther. 2011:19:584-93.

33. Yeung ATY, Hale C, Lee AH, Gill EE, Bushell W, Parry-Smith D, et al. Exploiting induced pluripotent stem cell-derived macrophages to unravel host factors influencing Chlamydia trachomatis pathogenesis. Nat Commun. 2017:8:15013.

34. Brault J, Goutagny E, Telugu N, Shao K, Baquie M, Satre V, et al. Optimized generation of functional neutrophils and macrophages from patient-specific induced pluripotent stem cells: ex vivo models of X(0)-linked, AR22(0)- and AR47(0)- chronic granulomatous diseases. BioRes Open Access. 2014:3:311-26.

35. Brault J, Vaganay G, Le Roy A, Lenormand JL, Cortes S, Stasia MJ. Therapeutic effects of proteoliposomes on X-linked chronic granulomatous disease: proof of concept using macrophages differentiated from patient-specific induced pluripotent stem cells. Int J Nanomedicine. 2017;12:2161-77.

36. Gupta RM, Meissner TB, Cowan CA, Musunuru K. Genome-edited human pluripotent stem cell-derived macrophages as a model of reverse cholesterol transport-brief report. Arterioscler Thromb Vasc Biol. 2016:36:15-8.

37. Jerebtsova M, Kumari N, Xu M, de Melo GB, Niu X, Jeang KT, et al. HIV-1 resistant CDK2-knockdown macrophage-like cells generated from 293T cell-derived human induced pluripotent stem cells. Biology. 2012;1:175-95.

38. Lachmann N, Ackermann M, Frenzel E, Liebhaber S, Brennig S, Happle C, et al. Large-scale hematopoietic differentiation of human induced pluripotent stem cells provides granulocytes or macrophages for cell replacement therapies. Stem Cell Rep. 2015;4:282-96.

39. Subramanian A, Guo B, Marsden MD, Galic Z, Kitchen S, Kacena A, et al. Macrophage differentiation from embryoid bodies derived from human embryonic stem cells. J Stem Cells. 2009;4:29-45.

40. Lu Y, Zhang TF, Shi Y, Zhou HW, Chen Q, Wei BY, et al. PFR peptide, one of the antimicrobial peptides identified from the derivatives of lactoferrin, induces necrosis in leukemia cells. Sci Rep. 2016:6:20823.

41. Keiser TL, Purdy GE. Killing Mycobacterium tuberculosis in vitro: what model systems can teach us. Microbiol Spectr. 2017;5 https://doi.org/10.1128/ microbiolspec.

42. Ackermann M, Kuhn A, Kunkiel J, Merkert S, Martin U, Moritz T, et al. Ex vivo generation of genetically modified macrophages from human induced pluripotent stem cells. Transfus Med Hemother. 2017:44:135-42.

43. Arango Duque G, Descoteaux A. Macrophage cytokines: involvement in immunity and infectious diseases. Front Immunol. 2014;5:491.

\section{Submit your next manuscript to BioMed Central and we will help you at every step:}

- We accept pre-submission inquiries

- Our selector tool helps you to find the most relevant journal

- We provide round the clock customer support

- Convenient online submission

- Thorough peer review

- Inclusion in PubMed and all major indexing services

- Maximum visibility for your research

Submit your manuscript at www.biomedcentral.com/submit 